\title{
The remarkable slenderness of flax plant and pertinent factors affecting its mechanical stability
}

\author{
Camille Goudenhooft ${ }^{a}$, Tancrède Alméras ${ }^{b}$, Alain Bourmaud ${ }^{a, *}$, Christophe Baley $^{a}$ \\ a Univ. Bretagne Sud, UMR CNRS 6027, IRDL, F-56100 Lorient, France \\ ${ }^{\mathrm{b}}$ LMGC, Université de Montpellier, CNRS UMR 5508, 34090 Montpellier, France
}

\begin{abstract}
Flax (Linum usitatissimum L.) is a plant of industrial interest. Its fibres have traditionally been used for textile applications and more recently, for composite reinforcement. To in-crease fibre yields, varietal selection has been used to develop varieties having high fibre content while retaining good resistance to lodging. This selection process has led to impressively slender structures of flax compared to other herbaceous plants. The present study focuses on the mechanical stability of flax related to its specific architecture. An anatomical study of transverse sections provides information about the architecture of flax stems, including the repartition of the internal reinforcing tissues being phloem fibres and xylem. Then, by using three-point bending tests, flexural modulus is evaluated along the stem. The safety factor (SF) against buckling for the plant was estimated based on Greenhill's model, taking into account gradients in diameter, load, and elastic modulus. Although flax plants have an unusually slender structure, they are mechanically stable. The stability of the plant is ensured by a high stem flexural modulus. This originates from an external ring composed of highperformance fibres, while an inner thick porous xylem provides the plant with a high resistance to local buckling. This is useful information for breeders, demonstrating that it is possible to keep increasing fibre yield without jeopard-ising plant stability.
\end{abstract}

Keywords:

Biomechanics

Flax stem

Flexural stiffness

Slenderness

Stability

\section{Introduction}

Flax (Linum usitatissimum L.) has been cultivated for many centuries. It is highly valued for its fibres, which are used as a raw material to produce textiles, which has been the motivation for its varietal selection. This expertise started to be developed in the 1920s (Doré \& Varoquaux, 2006; Jankauskiene, 2014) with the aim of increasing the fibre production yield (Jankauskiene, 2014), improving the lodging stability (Gibaud, Bourmaud, \& Baley, 2015) and resistance against diseases (Spielmeyer, Lagudah, Mendham, \& Green, 1998). Although the influence of varietal selection can be currently seen in terms of effective production yields, it has also affected the plant's anatomy. The extraordinary mechanical properties of flax elementary fibres are stable with similar variability whatever the considered flax variety

\footnotetext{
* Corresponding author. Univ. Bretagne Sud, UMR CNRS 6027, IRDL, Rue de Saint-Maudé, F-56100 Lorient, France. Fax: +33 297874588. E-mail address: alain.bourmaud@univ-ubs.fr (A. Bourmaud).
} 


\begin{tabular}{|c|c|}
\hline \multicolumn{2}{|c|}{ Nomenclature } \\
\hline c & function of $n$ and $m$ \\
\hline$d$ & span length (mm) \\
\hline$D$ & diameter of the stem $(\mathrm{mm})$ \\
\hline$\delta$ & deflection (mm) \\
\hline $\mathrm{dF} / \mathrm{dy}$ & slope of the linear part of the \\
\hline & force-displacement curve $\left(\mathrm{N} \mathrm{mm}^{-2}\right)$ \\
\hline e & thickness of the fibre ring $(\mu \mathrm{m})$ \\
\hline$E$ & $\begin{array}{l}\text { apparent flexural modulus of the stem or } \\
\text { modulus of elasticity (GPa) }\end{array}$ \\
\hline EI & flexural stiffness of the stem $\left(\mathrm{N} \mathrm{m}^{2}\right)$ \\
\hline$f$ & applied force during a bending test $(\mathrm{N})$ \\
\hline$F^{\prime}$ & form factor \\
\hline$g$ & acceleration due to gravity $\left(\mathrm{m} \mathrm{s}^{-2}\right)$ \\
\hline $\mathrm{H}$ & plant height (mm, m) \\
\hline $\mathrm{H}_{\mathrm{cr}}$ & critical buckling height $(\mathrm{m})$ \\
\hline I & second moment of area of the stem $\left(\mathrm{mm}^{4}\right)$ \\
\hline$I_{\text {fibres }}$ & $\begin{array}{l}\text { second moment of area of the fibrous ring } \\
\left(\mathrm{mm}^{4}\right)\end{array}$ \\
\hline K & proportionality constant \\
\hline$L$ & load factor $\left(\mathrm{kg} \mathrm{m}^{-3}\right)$ \\
\hline$m$ & load distribution parameter \\
\hline M & mass of the top load (g) \\
\hline$n$ & tapering parameter \\
\hline SF & safety factor \\
\hline$w$ & bulk density $\left(\mathrm{N} \mathrm{m}^{-3}\right)$ \\
\hline y & displacement at the middle of the sample $(\mathrm{mm})$ \\
\hline
\end{tabular}

(Goudenhooft, Bourmaud, \& Baley, 2017). This latter criterion is of great interest, since the use of flax fibres is no longer limited to the clothing industry. Indeed, flax technical fibres have served as reinforcement in composite materials since the late 1930s (de Bruyne, 1939). The numerous advantages of flax fibres justify modern application; for instance, flax fibres can now compete with glass fibres in terms of average specific mechanical performance (Baley \& Bourmaud, 2014) as well providing interest through their interesting acoustic behaviour (Merotte, Le Duigou, Bourmaud, Behlouli, \& Baley, 2016). In contrast to glass-fibre composites, flax fibres also ensure reduced environmental impacts when incorporated into flaxbased composite materials (Le Duigou, Davies, \& Baley, 2011).

In addition to their industrial advantages, flax stems possess outstanding morphological properties. The slenderness factor (i.e. the ratio between height and diameter of the stem) of flax has no competitor among botanical herbs (herbaceous plants) and trees. In fact, when compared to the 76 species of herb stems studied by Niklas (1995), flax possesses a much greater slenderness (Fig. 1) taking an average basal diameter of $3 \mathrm{~mm}$ and a total height of $1.17 \mathrm{~m}$ as measured in the present work. The value for flax given here refers to a recent variety and is based on plants cultivated using a conventional seeding rate, i.e. providing a compromise between fibre yield and plant stability (Bourmaud, Gibaud, \& Baley, 2016). Finally, although flax is an herb with a limited secondary growth, it appears to follow a scaling relationship more closely resembling trees rather than herbs plants, according

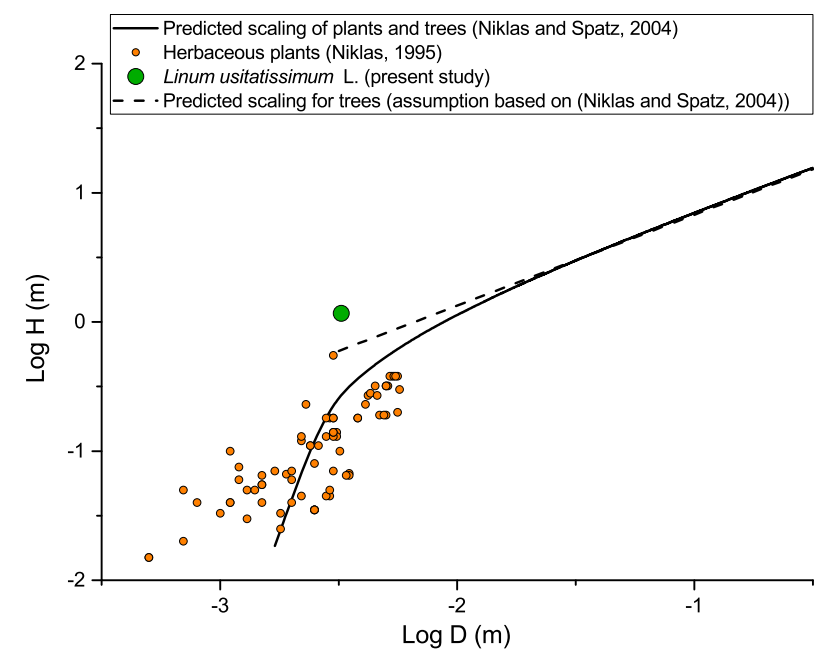

Fig. 1 - Scaling relationship for plant height $(H)$ and basal diameter (D) measured on flax (Linum usitatissimum $\mathrm{L}$ ) in this study, in comparison with herbaceous plants analysed by Niklas (1995) and using the predicted scaling of plants and trees given in Niklas and Spatz (2004) by $H=34.64 \times$ $D^{2 / 3}-0.475$. The assumption made here to predict the scaling of trees is based on (Niklas \& Spatz, 2004).

our understanding of the literature (Fig. 1) (Niklas \& Spatz, 2004).

With flax as well as other crop plants such as wheat or barley, lodging is a major problem as it compromises yield and quality (Berry \& Spink, 2012; Fischer \& Stapper, 1987; Vera et al., 2012). To quantify the impact of varietal selection on the lodging stability of flax stems, a crucial parameter to consider is the mechanical stability of the plant (McMahon, 1973). Indeed, for flax, the risk of lodging increases with rainfall and wind, but a high slenderness ratio also implies a risk of elastic buckling due to self-weight and additional loads such as rain. The degree of mechanical stability can be assessed through the safety factor (SF) against buckling, defined as the ratio between the critical buckling height and actual height of the plant (Niklas, 1994). The critical buckling height (Greenhill, 1881) is the maximum height that the plant can reach while remaining stable, given its diameter and material properties. In a study on tree saplings grown in a tropical environment (Jaouen, Alméras, Coutand, \& Fournier, 2007), showed that variations in critical buckling height also strongly depend on "form" parameters, namely the distribution of mass and diameters along the stem. The stability of the plant may also depend on gradients in mechanical properties along the stem.

This study investigates the stability of flax in order to understand how this plant can reach such a slender structure while remaining mechanically stable. The architecture of flax plants is studied through an anatomical analysis. This is followed by an examination of the mechanical stability of the plants which is assessed by determining their SF, taking into account the distribution of diameters and mass along the stem. Finally, the effect of gradients in elasticity modulus is investigated using a numerical model of buckling. 


\section{Material and methods}

\subsection{Plant materials and measurements}

Flax seeds (Bolchoï, textile variety selected in 2014) were provided by Terre de Lin (a flax cooperative in Normandy, France). Sowing was carried out outdoor in April 2016 in Lorient, France, using a conventional seeding density of about 1800 plants $\mathrm{m}^{-2}$ (Bourmaud et al., 2016). Ten stems were pulled out 100 days after sowing, a period corresponding to an accumulated temperature of $1010^{\circ} \mathrm{C}$ taken as indicating plant maturity (Goudenhooft et al., 2017). Immediately after being pulled out, the technical stem height (i.e. the part of the stem located below the first floral ramification) and the total height of each stem were determined using a measuring tape. The technical stem was then cut from the basal part into 4 portions of $200 \mathrm{~mm}$ to make the samples (the last portion was generally $<200 \mathrm{~mm}$ ). For each sample, the diameter was measured at mid-height using a calliper and its weight recorded; the inflorescence was also weighed. Stem segments were used for anatomical analysis and bending tests, as detailed below.

\subsection{Anatomical analysis}

Mature stem portions about $10 \mathrm{~mm}$ in length were cut from the middle of the $200-\mathrm{mm}$ samples collected from an average plant. These $10 \mathrm{~mm}$ samples were fixed in a solution of $4 \% \mathrm{v} / \mathrm{v}$ formaldehyde in $0.1 \mathrm{M}$ phosphate buffer $\left(\mathrm{pH}\right.$ 7.2) at $4{ }^{\circ} \mathrm{C}$ overnight. The samples were gradually dehydrated in a series of ethanol solutions. Then, samples were cleaned using increasing concentrations of Histoclear ${ }^{\circledR}$ (National Diagnostics $^{\mathrm{TM}}$, Thermo Fisher Scientific, Illkirch-Graffenstaden, France) in ethanol/Histoclear solutions. Later, samples were immersed in Histoclear/paraffin (Paraplast Plus ${ }^{\circledR}$, Leica, Wetzlar, Germany) baths with gradually increasing concentrations of paraffin. Samples were finally embedded in pure paraffin at $60{ }^{\circ} \mathrm{C}$ and immediately stored at $4{ }^{\circ} \mathrm{C}$. Sections (20 $\mu \mathrm{m}$ thick) were cut using a microtome (Leica RM2135 equipped with disposable blade) and placed on Superfrost Plus $^{\circledR}$ (Thermo Scientific ${ }^{\mathrm{TM}}$, Thermo Fisher Scientific, IllkirchGraffenstaden, France) slides on a hot plate $\left(35^{\circ} \mathrm{C}\right)$. Slides were stored at $40{ }^{\circ} \mathrm{C}$ overnight. Then, sections were dewaxed by immersion in two pure Histoclear baths followed by a series of solutions with decreasing ethanol concentrations. Finally, sections were rinsed in distilled water, stained with toluidine blue and covered with Eukitt ${ }^{\circledR}$ (Sigma-Aldrich, Saint-Quentin-Fallavier, France) and a glass coverslip.

The stained slides were observed under an optical microscope (Olympus AX70). Pictures were taken with an Olympus DP25 camera and anatomical parameters were analysed using image analysis. Namely, the outline of the central lacuna, of the xylem tissue and of each fibre bundle visible on pictures of stem cross-sections are manually drawn using Gimp ${ }^{\circledR}$ (GNU Image Manipulation Program, version 2.10.6 of the software). Then, the tissue content (\% of the stem area devoid of lacuna area) and the fibre content (total bundle area expressed in \% of the stem area and \% of tissue content) are automatically evaluated using Image ${ }^{\circledR}$ (version 1.51 of this image processing and analysis software in Java, developed by Wayne Rasband, National Institutes of Health, Bethesda, Maryland, USA). Finally, the average bundle thickness is calculated from 30 measurements around the stem cross-section with Image ${ }^{\circledR}$.

\subsection{Three-point bending tests}

Three-point bending tests were carried out on ten flax plants using a universal MTS (Eden Prairie, Minnesota, USA) tensile testing machine equipped with a $50 \mathrm{~N}$ capacity load cell. A displacement rate of $0.1 \mathrm{~mm} \mathrm{~s}^{-1}$ was used and a span length (d) of $180 \mathrm{~mm}$ was fixed to allow pure bending stress during tests, as demonstrated by Réquilé, Goudenhooft, Bourmaud, Le Duigou, \& Baley (2018). Tested stem samples were all $200 \mathrm{~mm}$ long, with a diameter of approximately $3 \mathrm{~mm}$, in order to be sufficiently slender to prevent significant shearing the stem.

Assuming the stem sample is a uniform beam, the displacement $(y)$ at the middle of the sample is given by Eq. (1) (Timoshenko, 1930):

$y=\frac{f d^{3}}{48 E I}$

where $f$ is the applied force, $d$ the span length and EI the flexural stiffness, while $E$ is the apparent flexural modulus and I the second moment of area given as $I=(\pi / 64) D^{4}$ for a circular cross-section of diameter $D$. This formula is exact for a cylindrical stem, but can be valid for a conical sample if the diameter at the middle is taken as the representative value (Alméras, Derycke, Jaouen, Beauchêne, \& Fournier, 2009). (2):

Finally, the apparent flexural modulus is obtained by Eq.

$E=\frac{d f}{d y} \cdot \frac{d^{3}}{48 I}$

where $d f / d y$ is the slope of the linear part of the force-displacement curve, from the beginning of the test and for small strains.

\subsection{Greenhill's model}

Greenhill's model (Greenhill, 1881) can be used to determine the "critical buckling height", i.e. the maximum height that a plant can reach while remaining stable, given its diameter $D$, elastic modulus $E$, and loads. The classically used formula is of the following form:

$H_{\mathrm{cr}}=K\left(\frac{E D^{2}}{\mathrm{w}}\right)^{\frac{1}{3}}$

where $\mathrm{K}$ is a proportionality constant depending on the distribution of diameters and loads and $w$ is the bulk density of the stem. Starting from Greenhill's initial formulation, the dependence of the critical buckling height in the distributions of diameters and masses can be made explicit. The trunk taper and load distribution are given by power laws characterised by parameters $n$ and $m$ as described in Jaouen et al. (2007) ( $n=0$ for a cylindrical stem and 1 for a conical stem, $m=0$ if load is concentrated at the top and 1 if load is uniformly distributed). Rearranging the equation of Jaouen et al. (2007), the critical buckling height $H_{\mathrm{cr}}$ can be expressed as: 
$H_{\mathrm{cr}}=\left(\frac{E \times F^{\prime 2} \times D^{2}}{64 g \times L}\right)^{\frac{1}{3}}$

where $g$ is the acceleration due to gravity, $L$ is a load factor defined as the ratio of total plant mass to stem volume, and $F^{\prime}$ is a form factor given by $F^{\prime}=c(n, m) \times|m-4 n+2| \times \sqrt{2 n+1}$, while $c$ is a function of $n$ and $m$ whose numerical expression can be found in Jaouen et al. (2007) (note that, because of a different formulation, $F^{\prime}$ slightly differs from the form factor $F$ defined in Jaouen et al. (2007)).

The critical buckling height of each plant was computed from Eq. (4), with $D$ being the diameter of the basal segment, $E$ the mean elastic modulus over the four tested segments. $L$ is estimated from the volume of the segments and the total mass of the plant, $n$ is obtained by log/log regression of the segment diameter versus its relative position along the stem and $m$ is computed so the height of the centre of mass of the modelled plant matches that of the real plant. The SF of each plant was obtained by dividing the critical buckling height by the real plant height $H$ :

$\mathrm{SF}=\frac{\mathrm{H}_{\mathrm{cr}}}{\mathrm{H}}$

\subsection{Effect of a gradient in elastic modulus}

Greenhill's model (Eq. (3)) assumes that the elastic modulus of the stem is uniform. However, gradients in elastic modulus along the stem may contribute to the stability of the plant. To test this hypothesis, a numerical buckling model that can be applied to any distribution of diameters, loads and elastic moduli along the stem is used. The principle of this model is to set an initial small disturbance (inclination angle of $1^{\circ}$ ) and compute the shape of the deformed stem submitted to its selfweight, accounting for the non-linear effect of large displacements. The related equations and algorithm are described by Alméras, Gril, and Costes (2002). If the plant is stable, the deflection remains small; if the plant is close to buckling, the deflection becomes large. This model is applied to the case of conical stem topped with a load corresponding to the inflorescence, setting average values of flax stem properties (Fig. 2(A)). The critical load of the plant was computed by varying the top load and calculating the deflection, and taken as the intersection point of the two regimes (Fig. 2(B)). To assess the effect of gradient in elastic modulus, this computation is carried out for a stem with uniform elastic properties, and for stems with variable gradients in elastic modulus, keeping the same average elastic modulus.

\section{Results}

All following results, as mentioned earlier, are based on the same 10 stems. This small sampling size can be justified by the fact that, in literature, similar stem architecture (height and diameter, thus slenderness too) as well as anatomy are obtained on stems from different varieties (Goudenhooft, Bourmaud, \& Baley, 2018; Goudenhooft et al., 2017; Réquilé et al., 2018). Moreover, fibres also exhibited the same range of mechanical properties whatever the cultivation year (Lefeuvre, Bourmaud, Lebrun, Morvan, \& Baley, 2013) or variety (Goudenhooft et al., 2017). Hence, the following results are assumed to be representative of the general behaviour of flax plants.

\subsection{Stem properties and anatomical analysis}

By taking into account the diameter of the very base of the stem and the related total stem height, the average slenderness $H / D$ of flax was evaluated to be $365 \pm 33$, highlighting the impressive feature of this plant. Changes in stem properties are then evaluated in samples collected along the stem, as
(A)

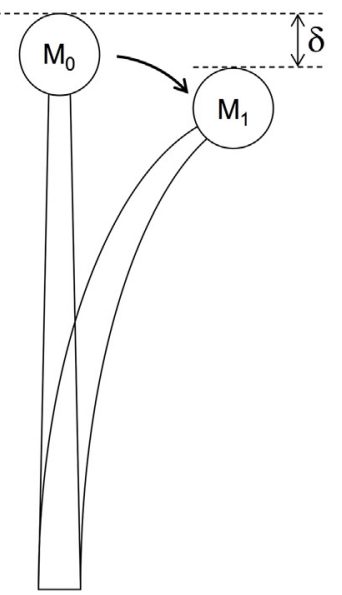

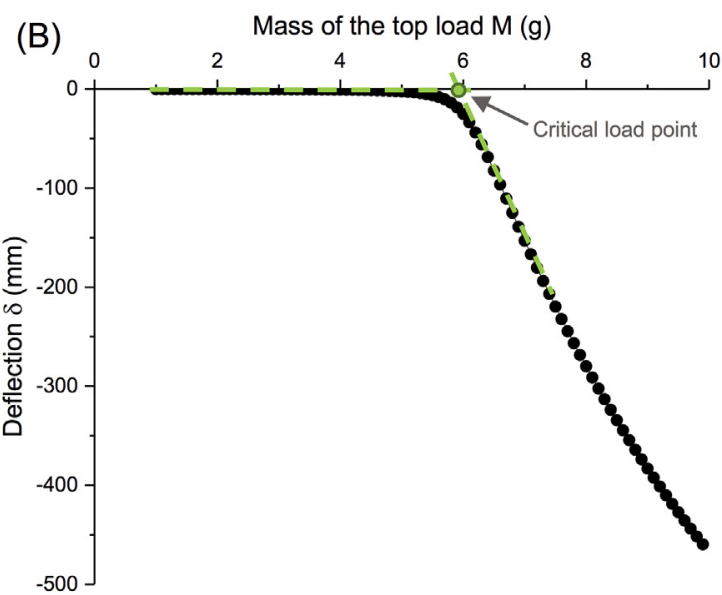

Fig. 2 - Numerical computation of the critical buckling height accounting for gradients in elastic modulus. (A) Representation of the plant as a conical stem topped with the load of inflorescence. When the top load $M$ is increased above the critical limit, the stem starts bending, yielding in a deflection $\delta$. (B) Deflection $\delta$ as a function of the top load M. The curve shows two regimes: below the critical load, the deflection remains small because the stem is loaded in pure compression; above the critical load, the stem bends and the deflection increases linearly. The critical load is computed as the intersection of these two lines. 
illustrated in Fig. 3(A), and the associated average characteristics are presented in Table 1.

The linear weight of the stem greatly decreases with height, varying on average from $7.06 \mathrm{mg} \mathrm{mm}^{-1}$ for the basal samples to $3.16 \times 10^{-3} \mathrm{mg} \mathrm{mm}^{-1}$ for the apical samples. This can be explained by the taper of the stem, reflecting the changes in diameter along the stem height, which decreases acropetally from $3.12 \mathrm{~mm}$ at a height of $100 \mathrm{~mm}$ to $2.09 \mathrm{~mm}$ at $700 \mathrm{~mm}$ (Fig. 3(A)). The internal structure of a representative cross-section is presented in Fig. 3(B), defining the different tissues that compose the flax stem. Based on the tissues mentioned in this latter figure, Table 2 gives the anatomical criteria corresponding to the cross-sections illustrated in Fig. 3(A).

This analysis only took into account the tissues having a mechanical key role, namely the fibre bundles and the xylem (Fig. 3(B)). The tissue content is at a maximum towards the base of the technical stem, whereas it reaches a minimum around mid-height i.e. around $500 \mathrm{~mm}$ height. The fibre content is lower in the basal region of the stem (Table 2) and does not change significantly between 300 and $700 \mathrm{~mm}$. Fibre bundles have a similar thickness along the stem despite the changes in stem diameter.

\subsection{Three-point bending test}

Samples from green stems were collected as illustrated in Fig. 3(A) and evaluated by three-point bending tests. Resulting properties are presented in Table 3.

The tests show that stem flexural stiffness increases with the diameter, i.e. the closer to the apex the tested sample, the lower the flexural stiffness. This latter parameter ranges from $0.013 \pm 0.006 \mathrm{~N} \mathrm{~m}^{2}$ in the top sample to $0.044 \pm 0.020 \mathrm{~N} \mathrm{~m}^{2}$ in the basal sample. The apparent flexural modulus sharply increases along the stem, from $8.7 \pm 0.5 \mathrm{GPa}$ for the basal segment to $12.9 \pm 1.8 \mathrm{GPa}$ for the apical segment (Fig. 4), with a mean gradient of $6.6 \mathrm{GPa} \mathrm{m} \mathrm{m}^{-1}$. These results reflect the gradient in mechanical properties along the stem.

In order to evaluate the influence of the fibres on the apparent flexural modulus of the stem, the fibre contribution to inertia was computed for each sample as:
Table 1 - Characteristics of flax stem samples along the stem; means and standard deviations are calculated on 10 tested plants.

\begin{tabular}{lccc} 
Sample & $\begin{array}{c}\text { Height } \\
(\mathrm{mm})\end{array}$ & $\begin{array}{c}\text { Linear weight } \\
\left(\mathrm{mg} \mathrm{mm}^{-1}\right)\end{array}$ & $\begin{array}{c}\text { Stem diameter } \\
(\mathrm{mm})\end{array}$ \\
\hline A & 100 & $7.06 \pm 2.01$ & $3.12 \pm 0.38$ \\
B & 300 & $5.08 \pm 1.58$ & $2.88 \pm 0.41$ \\
C & 500 & $3.83 \pm 0.93$ & $2.56 \pm 0.41$ \\
D & 700 & $3.16 \pm 0.90$ & $2.09 \pm 0.34$ \\
\hline
\end{tabular}

Table 2 - Analyses of stem samples corresponding to transverse sections visible in Fig. 3(A) for illustrative purposes.

\begin{tabular}{lcccc} 
Sample & $\begin{array}{c}\text { Tissue } \\
\text { content } \\
(\% \text { of stem } \\
\text { area })\end{array}$ & $\begin{array}{c}\text { Fibre } \\
\text { content } \\
(\% \text { of stem } \\
\text { area })\end{array}$ & $\begin{array}{c}\text { Fibre } \\
\text { content } \\
(\% \text { of tissue } \\
\text { area })\end{array}$ & $\begin{array}{c}\text { Bundle } \\
\text { thickness } \\
(\mu \mathrm{m})\end{array}$ \\
\hline A & 68 & 17 & 25 & $77 \pm 8$ \\
B & 62 & 21 & 34 & $82 \pm 12$ \\
C & 55 & 20 & 36 & $83 \pm 8$ \\
D & 63 & 23 & 36 & $73 \pm 11$ \\
\hline
\end{tabular}

Fibre contribution $\left.(\%)=\frac{I_{\text {fibres }}}{I} \times 100=1-\left(1-\frac{2 e}{D}\right)^{4}\right) \times 100$

where $I$ is the second moment of area of the stem sample (previously defined), $I_{\text {fibres }}$ is the second moment of area of the fibrous ring, $D$ is the sample average diameter and $e$ is the thickness of the fibre ring given by the average thickness of the fibre bundles (Table 2). The relation between the fibre contribution and the apparent flexural modulus of the stem is illustrated in Fig. 4. This graph shows that the gradient in apparent flexural modulus along the stem is mainly driven by the variation in fibre contribution. In fact, this gradient results from the distribution of fibres along the stem; the thickness of the fibre bundles is almost unchanged whereas the diameter decreases along the stem.

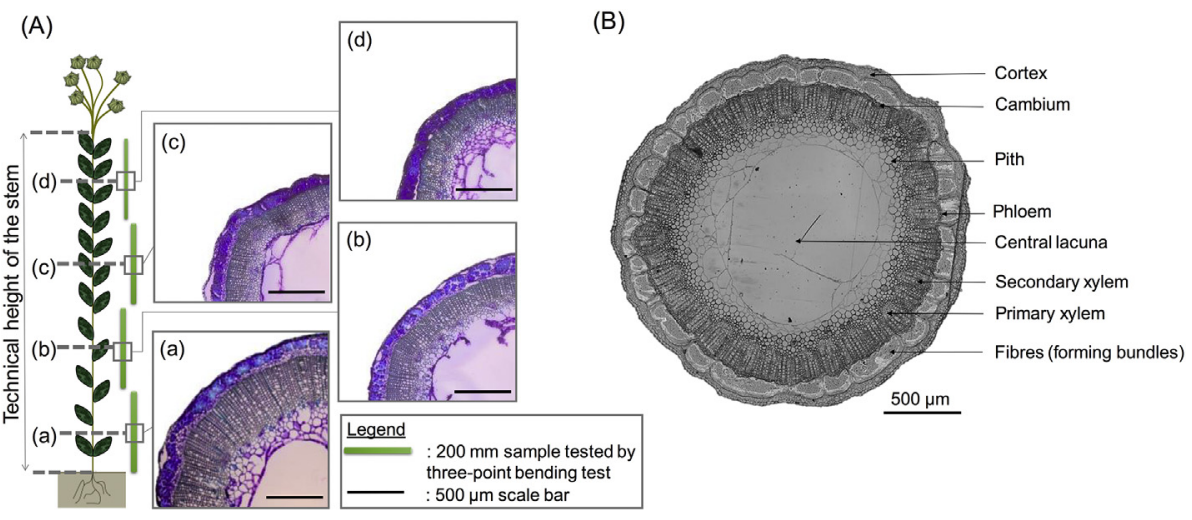

Fig. 3 - (A) Schematic diagram of sampling along a flax stem and associated transverse sections (a,b, c and d) of a single plant, with (a) being the basal sample and (d) the apical one. (B) Description of different tissues of a transverse stem section. 
Table 3 - Characteristics of flax stem samples along the stem obtained from three-point bending test. Means and standard deviation are calculated on $\mathbf{1 0}$ tested plants.

\begin{tabular}{lccc} 
Sample & $\begin{array}{c}\text { Second } \\
\text { moment of } \\
\text { area }\left(\mathrm{mm}^{4}\right)\end{array}$ & $\begin{array}{c}\text { Flexural } \\
\text { stiffness } \\
\left(\mathrm{N} \mathrm{m}^{2}\right)\end{array}$ & $\begin{array}{c}\text { Apparent flexural } \\
\text { modulus }(\mathrm{GPa})\end{array}$ \\
\hline $\mathrm{a}$ & $5.0 \pm 2.3$ & $0.044 \pm 0.020$ & $8.7 \pm 0.5$ \\
$\mathrm{~b}$ & $3.7 \pm 1.9$ & $0.036 \pm 0.016$ & $10.0 \pm 1.1$ \\
$\mathrm{c}$ & $2.3 \pm 1.1$ & $0.024 \pm 0.016$ & $10.5 \pm 1.1$ \\
$\mathrm{~d}$ & $1.1 \pm 0.6$ & $0.013 \pm 0.006$ & $12.9 \pm 1.8$ \\
\hline
\end{tabular}

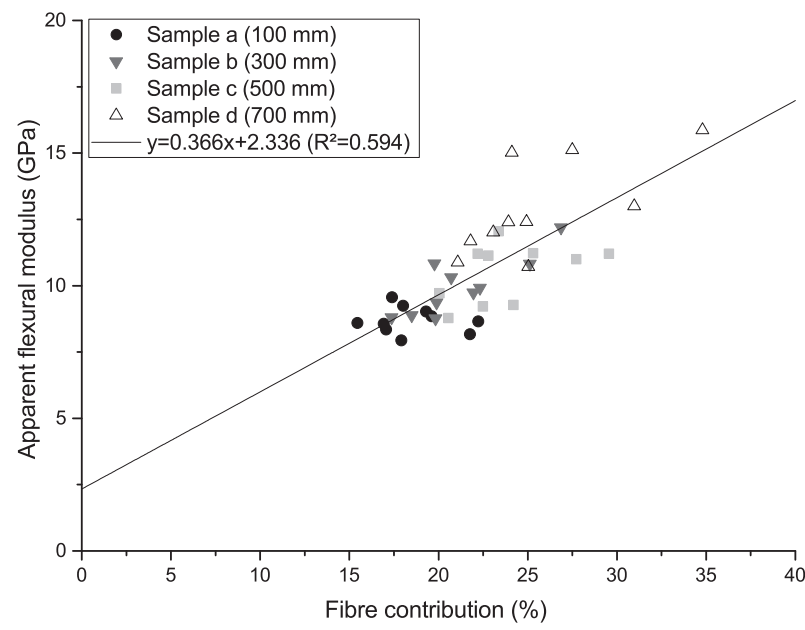

Fig. 4 - Apparent flexural modulus of green flax stem samples plotted against the contribution of fibres to the second moment of inertia of the stem; a linear regression can be calculated with its intercept fixed at zero $\left(R^{2}=0.985\right.$; $P<0.05$ ).

\subsection{Safety against buckling}

Measurements carried out on green stems yield a total plant height of $1.17 \pm 0.04 \mathrm{~m}$ for an average diameter of $3.24 \pm 0.37 \mathrm{~mm}$ at the very base of the stems, and a total weight of $5.76 \pm 1.65 \mathrm{~g}$, while the average apparent flexural modulus of the samples is estimated at $10.5 \pm 0.84 \mathrm{GPa}$ by bending tests. The SF against buckling ranges between 1.30 and 1.60 , with a mean value of 1.44 . The fact that $S F>1$ for all plants implies that the flax plants were stable, in agreement with field observations showing their self-supporting habit. The taper coefficient $(n)$ was close to $0.5(0.49 \pm 0.07)$, indicating that the flax stems have a paraboloid shape. The load distribution parameter $(m)$ of $1.08 \pm 0.05$, i.e. close to unity, indicates that the centre of mass of the plant is located near its mid-height. The load factor (L) was estimated at $1159 \pm 82 \mathrm{~kg} \mathrm{~m}^{-3}$.

\subsection{Effect of elastic modulus gradient}

Figure 5 shows the effect of an elastic modulus gradient on the stability of flax plants. From a qualitative viewpoint, the curve presents an optimum near $-2 \mathrm{GPa} \mathrm{m}^{-1}$, implying that the plant is more stable if the modulus of elasticity decreases slightly along the stem, so a strong positive gradient would

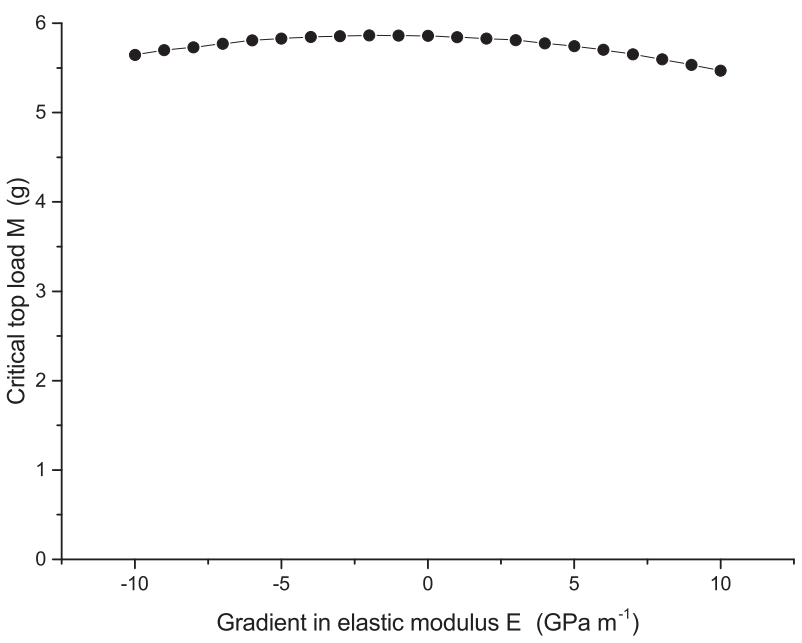

Fig. 5 - Effect of elastic modulus gradient (for a fixed average elastic modulus) on the stability of flax, numerically evaluated by changes in the critical load.

mean that the situation of the flax stem is suboptimal. However, from a quantitative viewpoint, it appears that this effect is negligible. The strong positive gradient of $+6.6 \mathrm{GPa} \mathrm{m}^{-1}$ observed in flax only reduces the critical load by approximately $3 \%$ compared to the optimum situation.

\section{Discussion}

The specific morphology of flax enables it to be much taller than other herbs of the same basal diameter, as illustrated on Fig. 1, while staying mechanically stable. The constraint of mechanical stability has implications in terms of how height scales to diameter. Substituting Eq. (4) into Eq. (5), it can be shown that, in order to ensure a given SF against buckling, plants of different size must scale such that $\mathrm{H}^{3} \sim \mathrm{D}^{2}$, provided intensive parameters (form factors, load factor and modulus of elasticity) do not change with size. This scaling law corresponds to a straight line on Fig. 1 , with a slope of $2 / 3$. The dotted line in Fig. 1 represents the observed scaling relationship between diameter and height of trees, for which the slope is equal to $2 / 3$, suggesting that trees of different size have a constant SF against buckling. That most herbs do not align with this line can be ascribed to the fact that intensive parameters, such as the modulus of elasticity, are not actually the same as in trees. The modulus of elasticity of herbs is usually much lower than for trees (Herrel, Speck, \& Rowe, 2006; Leblicq, Vanmaercke, Ramon, \& Saeys, 2015; Niklas, 1995; O'Dogherty, Huber, Dyson, \& Marshall, 1995). This lower performance is reflected by the fact that all the herbs studied by Niklas (1995) lie below the line of trees. Flax, however, appears aligned with trees in Fig. 1, suggesting that it competes with trees in terms of its performance regarding intensive parameters.

The taper coefficient $(n)$, close to 0.5 , is slightly lower than the mean value of 0.66 observed by Jaouen et al. (2007) for forest tree saplings. The load distribution parameter $(m)$ is close to unity, and lower than the average value of $1.62 \mathrm{ob}-$ tained by Jaouen et al. (2007), indicating that the relative 
position of the centre of mass is higher in flax than in tree saplings. This is due to the concentration of loads near the top, caused by the terminal inflorescence, so the load distribution should have a negative effect on the stability of flax. The load factor $(L)$ is $1159 \mathrm{~kg} \mathrm{~m}^{-3}$, which is slightly lower than the value of 1340 obtained by Jaouen et al. (2007). This low value is due to the low bulk stem density (on average, about $850 \mathrm{~kg} \mathrm{~m}^{-3}$ for the technical stem) of flax compared to trees. This low load factor is beneficial for the stability of flax plants. The apparent flexural modulus of flax stems (10.5 GPa in average) is much higher than other herbs (Herrel et al., 2006; Leblicq et al., 2015; Niklas, 1995; O'Dogherty et al., 1995) and closer to woody plants including self-supporting trees and shrubs (Speck \& Burgert, 2011). For green wood, the flexural modulus typically ranges between 5 and $20 \mathrm{GPa}$ (Kretschmann, 2010). The values obtained on flax stems are thus comparable with the modulus of trees. This flexural modulus, exceptionally high for an herb, explains why flax is aligned with trees on Fig. 1; it is related to the specific architecture of flax stem, namely to the presence of an external ring of fibres with extraordinary mechanical properties. If the mechanical contribution of tissues other than phloem fibres is neglected, the relationship shown on Fig. 4 would yield an apparent modulus of $46.7 \mathrm{GPa}$ for green fibres. This value is slightly lower than that given in the literature for dehydrated flax fibres, namely $52.5 \pm 8.6 \mathrm{GPa}$ (Baley \& Bourmaud, 2014), but consistent with the apparent tensile modulus obtained on green fibres, namely $45.3 \pm 9.7 \mathrm{GPa}$ (Goudenhooft, Siniscalco, et al., 2018). This present result confirms that the high flexural modulus of the flax plant can be attributed to the performance of its fibres. Moreover, the distribution of these fibres within the section make them a very efficient reinforcement. Indeed, the contribution of a fibre to the flexural stiffness depends on its distance to the neutral line of the section, which is positioned at its centre. Being located at the periphery of the section, phloem fibres are optimally positioned to provide the stem with high flexural stiffness.

The observed gradient in flexural modulus along flax stems is directly related to constraints of stem anatomy. The development of flax phloem fibres is such that they form a continuous ring of fixed thickness, irrespective of the diameter of the section (Table 2). As a consequence, the relative contribution of fibres to inertia is larger for sections of smaller diameter (Fig. 4), located in apical parts of the stem. As fibres are the main contributor to flexural stiffness, the flexural modulus follows the same pattern and the gradient in flexural modulus is a consequence of the constancy of the fibre ring thickness. The numerical analysis (Fig. 5) shows that this gradient has very low impact on the mechanical stability of the plants. Compared to a situation where the flexural modulus would be constant (for example if the fibre ring thickness was proportional to the section diameter), the mechanical stability of flax is reduced by only a few percent. This shows that the distribution of fibres along the stem, contrary to their distribution within the section, is mostly neutral in terms of plant stability. Concentrating fibres in basal or apical parts does not impact the mechanical stability. This is because all parts of the plant, basal and apical, actually contribute equally to the bending of the plant. Indeed, basal parts are submitted to larger loads, but also have a larger inertia because of their larger diameter. Apical parts are less loaded but also have a lower inertia. Reinforcing a part of the stem at the expense of another results in compensation of the contributions of these two parts, and it does not affect the overall stability of the plant.

The key to the mechanical performance of flax stems lies in the performance of its fibres, and in their optimal distribution within the section. It can be easily shown that, for a given amount of fibres, the specific core-rind structure set during flax growth maximises flexural stiffness. This is a well-known fact in engineering sciences; for a given amount of material, a tubular structure is more efficient than a cylindrical structure. This strategy has, however, some drawbacks as in a tubular structure, the risk of stem ovalisation and local buckling appears (Baley, Goudenhooft, Gibaud, \& Bourmaud, 2018). In the case of flax, this risk is prevented by the presence of an inner layer of xylem. Data from Fig. 3 and Table 2 show that the xylem area is reaches a maximum in the basal parts of the stem. This efficiently prevents the problem of local buckling in the basal part of the stem, where the risk is highest because of the lowest relative thickness of the fibre ring at that level.

\section{Conclusions}

Compared to other plants and trees, the flax plant is a remarkable structure which despite considerable slenderness is mechanically stable. The stability of the flax plant can be explained by the high apparent flexural modulus of the stem (maximum values of $12.9 \pm 1.8 \mathrm{GPa}$ for the apical part of the technical stem). This is much higher than observed in other herbs. The difference in this modulus could be related to the fibrous external ring formed by the fibre bundles within the flax stem. This ring accounts for a flexural modulus reaching values comparable with that of trees. In addition, although to a lesser extent, other parameters are favourable for the stability of flax; namely, its paraboloid shape (reflected by a taper coefficient of 0.5 ) and a rather low load factor of $1159 \mathrm{~kg} \mathrm{~m}^{-3}$ when compared with trees. Moreover, the unusually high centre of mass reduces the stability of the plant only by a small extent. Finally, varietal selection of flax over many years and cultural practices such as planting density have led to increases in fibre yield and lodging resistance, giving rise to its current extremely slender but mechanically stable structure. The uncommon characteristics of flax makes make it a very instructive model for bioinspired materials. Better monitor the lodging behaviour of the stem, complementary investigations about the SF during ontogeny as well as the influence of the variety on the mechanical stability will be performed in further studies.

\section{Acknowledgements}

The authors thank OSEO and the French Ministry of Higher Education and Research for their financial support. Dr. M.S.N. Carpenter post-edited the English style and grammar. 
Jaouen, G., Alméras, T., Coutand, C., \& Fournier, M. (2007). How to determine sapling buckling risk with only few measurements. American Journal of Botany, 94(10), 1583-1593.

Alméras, T., Derycke, M., Jaouen, G., Beauchêne, J., \& Fournier, M. (2009). Functional diversity in gravitropic reaction among tropical seedlings in relation to ecological and developmental traits. Journal of Experimental Botany, 60(15), 4397-4410. https:// doi.org/10.1093/jxb/erp276.

Alméras, T., Gril, J., \& Costes, E. (2002). Bending of apricot tree branches under the weight of axillary growth: Test of a mechanical model with experimental data. Trees - Structure and Function, 16(1), 5-15. https://doi.org/10.1007/s00468-001-0139-1.

Baley, C., \& Bourmaud, A. (2014). Average tensile properties of French elementary flax fibers. Materials Letters, 122, 159-161. https://doi.org/10.1016/j.matlet.2014.02.030.

Baley, C., Goudenhooft, C., Gibaud, M., \& Bourmaud, A. (2018). Flax stems: From a specific architecture to an instructive model for bioinspired composite structures. Bioinspiration \& Biomimetics, 13(2), 026007. https://doi.org/10.1088/1748-3190/aaa6b7.

Berry, P. M., \& Spink, J. (2012). Predicting yield losses caused by lodging in wheat. Field Crops Research, 137, 19-26. https:// doi.org/10.1016/j.fcr.2012.07.019.

Bourmaud, A., Gibaud, M., \& Baley, C. (2016). Impact of the seeding rate on flax stem stability and the mechanical properties of elementary fibres. Industrial Crops and Products, 80, 17-25. https://doi.org/10.1016/j.indcrop.2015.10.053.

de Bruyne, N. A. (1939). Plastic progress - Some further developments in the manufacture and use of synthetic materials for aircraft construction. Flight: The Aircraft Engineer, (January 12), 77-79.

Doré, C., \& Varoquaux, F. (2006). Le lin. In Histoire et amélioration de cinquante plantes cultivées (pp. 383-396). INRA-QUAE.

Fischer, R. A., \& Stapper, M. (1987). Lodging effects on highyielding crops of irrigated semidwarf wheat. Field Crops Research, 17(3-4), 245-258. https://doi.org/10.1016/03784290(87)90038-4.

Gibaud, M., Bourmaud, A., \& Baley, C. (2015). Understanding the lodging stability of green flax stems; the importance of morphology and fibre stiffness. Biosystems Engineering, 137, 9-21. https://doi.org/10.1016/j.biosystemseng.2015.06.005.

Goudenhooft, C., Bourmaud, A., \& Baley, C. (2017). Varietal selection of flax over time: Evolution of plant architecture related to influence on the mechanical properties of fibers. Industrial Crops and Products, 97, 56-64. https://doi.org/10.1016/ j.indcrop.2016.11.062.

Goudenhooft, C., Siniscalco, D., Arnould, O., Bourmaud, A., Sire, O., Gorshkova, T., et al. (2018). Investigation of the mechanical properties of flax cell walls during plant development: The relation between performance and cell wall structure. Fibers, 6(1), 6. https://doi.org/10.3390/fib6010006.

Greenhill, A. G. (1881). Determination of the greatest height consistent with stability that a vertical pole or mast can be made, and the greatest height to which a tree of given proportions can grow. Proceedings of the Cambridge Philosophical Society, 4, 65-73.

Herrel, A., Speck, T., \& Rowe, N. P. (2006). In A. Herrel, T. Speck, \& N. P. Rowe (Eds.), A mechanical approach to the ecology of animals and plants. Taylor \& Francis.

Jankauskiene, Z. (2014). Results of 90 years of flax breeding in Lithuania. Proceedings of the Latvian Academy of Sciences. Section B: Natural, Exact and Applied Sciences, 68(3-4), 184-192. https:// doi.org/10.2478/prolas-2014-0022.

Kretschmann, D. E. (2010). Mechanical properties of wood (Chapter 5). In Wood handbook - Wood as an engineering material. General technical report FPL-GTR-190 (pp. 1-46). Washington: US Department of Agriculture.

Le Duigou, A., Davies, P., \& Baley, C. (2011). Environmental impact analysis of the production of flax fibres to be used as composite material reinforcement. Journal of Biobased Materials and Bioenergy, 5(1), 153-165. https://doi.org/10.1166/ jbmb.2011.1116.

Leblicq, T., Vanmaercke, S., Ramon, H., \& Saeys, W. (2015). Mechanical analysis of the bending behaviour of plant stems. Biosystems Engineering, 129, 87-99. https://doi.org/10.1016/ j.biosystemseng.2014.09.016.

Lefeuvre, A., Bourmaud, A., Lebrun, L., Morvan, C., \& Baley, C. (2013). A study of the yearly reproducibility of flax fiber tensile properties. Industrial Crops and Products, 50. https://doi.org/ 10.1016/j.indcrop.2013.07.035.

McMahon, T. (1973). Size and Shape in Biology. Elastic criteria impose limits on biological proportions, and consequently on metabolic rates. Science, 179(4079), 1201-1204. https://doi.org/ 10.1017/CBO9781107415324.004.

Merotte, J., Le Duigou, A., Bourmaud, A., Behlouli, K., \& Baley, C. (2016). Mechanical and acoustic behaviour of porosity controlled randomly dispersed flax/PP biocomposite. Polymer Testing, 51, 174-180. https://doi.org/10.1016/ j.polymertesting.2016.03.002.

Niklas, K. J. (1994). Interspecific allometries of critical buckling height and actual plant height. American Journal of Botany, 81(10), 1275-1279. https://doi.org/10.2307/2445403.

Niklas, K. J. (1995). Plant height and the properties of some herbaceous stems. Annals of Botany, 75, 133-142.

Niklas, K. J., \& Spatz, H.-C. (2004). Growth and hydraulic (not mechanical) constraints govern the scaling of tree height and mass. Proceedings of the National Academy of Sciences of the United States of America, 101(44), 15661-15663. https://doi.org/10.1073/ pnas.0405857101.

O'Dogherty, M. J., Huber, J. A., Dyson, J., \& Marshall, C. J. (1995). A study of the physical and mechanical properties of wheat straw. Journal of Agricultural Engineering Research, 62, 133-142.

Réquilé, S., Goudenhooft, C., Bourmaud, A., Le Duigou, A., \& Baley, C. (2018). Exploring the link between flexural behaviour of hemp and flax stems and fibre stiffness. Industrial Crops and Products, 113(January), 179-186. https://doi.org/10.1016/j. indcrop.2018.01.035.

Speck, T., \& Burgert, I. (2011). Plant stems: Functional design and mechanics. Annual Review of Materials Research, 41, 169-193. https://doi.org/10.1146/annurev-matsci-062910-100425.

Spielmeyer, W., Lagudah, E. S., Mendham, N., \& Green, A. G. (1998). Inheritance of resistance to flax wilt (Fusarium oxysporum f.sp. lini Schlecht) in a doubled haploid population of Linum usitatissimum L. Euphytica, 101, 287-291. https:// doi.org/10.1023/A:1018353011562.

Timoshenko, S. P. (1930). In N. Van (Ed.), Strength of materials - Part 2 - Advanced theory and problems. van Nostrand.

Vera, C. L., Duguid, S. D., Fox, S. L., Rashid, K. Y., Dribnenki, J. C. P., \& Clarke, F. R. (2012). Short Communication: Comparative effect of lodging on seed yield of flax and wheat. Canadian Journal of Plant Science, 92(1), 39-43. https://doi.org/10.4141/ cjps2011-031. 